SSC-MAG-199

LBL -25265

\title{
DEVELOPMENT OF SUPERCONDUCTING STRAND AND CABLE WITH IMPROVED PROPERTIES FOR USE IN SSC MAGNETS*
}

Ronald M. Scanlan

Accelerator \& Fusion Research Division

Lawrence Berkeley Laboratory

1 Cyclotron Road

Berkeley, CA 94720

February 1989

*This work is supported by the Office of Enertgy Research, Office of High Energy and Nuclear Physics, High Energy Physics Division, Dept. of Energy under Contract No. DEAC03-76SF00098. 
SSC-MAG- 199

LBL -25265

DEVELOPMENT OF SUPERCONDUCTING STRAND AND CABLE WITH IMPROVED PROPERTIES FOR USE IN SSC MAGNETS*

\author{
Ronald M. Scanlan \\ Lawrence Berkeley Laboratory \\ 1 Cyclotron Road \\ Berkeley, CA 94720
}

\begin{abstract}
The critical current requirement for the NbTi superconductor strand was set at $2750 \mathrm{~A} / \mathrm{mm}^{2}$ $(5 \mathrm{~T}, 4.2 \mathrm{~K})$ in the SSC Conceptual Design, compared with a value of $1800 \mathrm{~A} / \mathrm{mm}^{2}$ which was specified for the strand used in the Tevatron dipoles. In addition, a filament diameter of $5 \mu \mathrm{m}$, instead of the $9 \mu \mathrm{m}$ diameter used in the Tevatron, was chosen to reduce field distortion at injection. In order to meet the requirements for field homogeneity, the dimensional requirements for both strand and cable were also tightened. The technical solutions employed to achieve these improved properties and the resulting specifications will be discussed.
\end{abstract}

\title{
DISCUSSION
}

The present SSC dipole design is a descendent of a design originally developed at LBL in late 1983/early 1984 as the LBL proposal for the SSC dipole. This design drew upon earlier dipoles built at FNAL for the Tevatron and at DESY for the HERA accelerator, together with an extrapolation of key parameters, where such extrapolation appeared reasonable in light of new technical developments. An example of this process are the choices of copper to superconductor ratio and number of strands in the cable. Discussions with the strand manufacturers and actual coil winding experience at $\mathrm{LBL}$ indicated that a $\mathrm{Cu} / \mathrm{SC}$ ratio of 1.0 was possible to fabricate, but presented problems for reliable large scale manufacturing and coil winding. On the other hand, a $\mathrm{Cu} / \mathrm{SC}$ ratio of 1.8 was considered as quite conservative, since the Tevatron magnets and their successors (CBA, HERA, and UNK) had all demonstrated the relative ease in working with this ratio. Hence, a ratio of 1.3 was chosen as a value which would extend the state of the art, yet which would meet the requirements for strand fabricability and coil winding.

The choice of number of strands and strand diameter resulted from similar considerations. Fabricability of a 23-strand cable had been demonstrated by the Tevatron cable; the main change introduced into the SSC design was a larger strand diameter (.0318") as compared with .0268" diam., and the above mentioned decrease in the $\mathrm{Cu} / \mathrm{SC}$ ratio. The larger strand diameter is beneficial in achieving a high overall current density and a high operating current, at a price of somewhat increased difficulty in coil winding. Another important cable parameter is keystone angle, and the choice here is a trade-off between the ideal (large) value

* This work is supported by the Office of Energy Research, Office of High Energy and Nuclear Physics, High Energy Physics Division, Dept. of Energy under Contract No. DE-AC03-76SF00098. 
that is associated with a small bore dipole and a small (or zero) value that yields minimum critical current degradation during cabling. Trial cable was made by SSC with the ideal keystone angle of $2.05^{\circ}$ for the inner cable and $1.57^{\circ}$ for the outer. Both cables showed a large degradation as indicated by many broken filaments, so the decision was made to reduce the angle until acceptable cable was achieved. The values found acceptable are $1.6^{\circ}$ for the inner cable and $1.2^{\circ}$ for the outer. It is interesting to note that several years later, designers of the RHIC dipoles elected to modify the SSC outer cable to produce a fully keystoned design with a $1.6^{\circ}$ angle. The excessive critical current degradation experienced with these cables forced them to return to the $1.2^{\circ}$ angle chosen for the SSC outer cable.

The most important parameter to choose in terms of the ultimate performance of the magnet is the critical current density. The experience base (again, the Tevatron dipoles) indicated that a minimum value of $1800 \mathrm{~A} / \mathrm{mm}^{2}$ at $5 \mathrm{~T}, 4.2 \mathrm{~K}$ could be achieved in production. However, new R\&D results from Baoji Institute (China) ${ }^{(1)}$ indicated that, with proper processing, values in excess of $3000 \mathrm{~A} / \mathrm{mm}^{2}$ at $5 \mathrm{~T}, 4.2 \mathrm{~K}$ are possible. Since this magnet was being proposed for a machine to be built in the 1990's, it was reasonable to assume that an aggressive R\&D program aimed at improved critical current density could be completed in time to provide the necessary conductor. Accordingly, a value of $2400 \mathrm{~A} / \mathrm{mm}^{2}$ was chosen as a design value and an $R \& D$ program was initiated in order to demonstrate that this value could be achieved in production-size billets (10" diam.). In June, 1984, this value was exceeded in a production-scale billet ${ }^{(2)}$ funded by LBL, and processed by Intermagnetics General Corp. (IGC) following a heat-treatment schedule proposed by D. Larbalestier (U. Wisconsin).

The selection of parameters for the outer layer cable follows logically from the inner layer cable parameters, since we want to match the operating current and quench protection in the two layers. Accordingly, the $\mathrm{Cu} / \mathrm{SC}$ ratio can be increased (this also reduces the cost of the cable), and the strand diameter reduced in order to increase the flexibility of the cable. The $\mathrm{Cu} / \mathrm{SC}$ ratio was increased to 2.0 , and a 30 -strand cable was proposed, although a 30 -strand cable had not yet been made in a long length.

These parameters remained basically unchanged during the next 18 months, while a series of $1-\mathrm{m}$ models at LBL and $4.5 \mathrm{~m}$ magnets at BNL were being built. One minor change was in the outer layer $\mathrm{Cu} / \mathrm{SC}$ ratio, from 2.0 to 1.8 , in order to more closely match the inner and outer cable critical currents. During this period, a total of 9 billets 10 " in diam. and 5 billets 12 " in diam. were produced for the SSC R\&D program and all met the minimum 2400 $\mathrm{A} / \mathrm{mm}^{2}$ critical current value.

In parallel with this effort, $R \& D$ work was begun in October, 1984, to explore the possibility of producing a fine filament NbTi conductor. The first R\&D contract $(3)$ was placed with Supercon, Inc. for the fabrication of a 12 " diam. billet to produce a conductor with 4000 filaments, with a minimum $\mathrm{J}_{\mathrm{C}}$ value of $2400 \mathrm{~A} / \mathrm{mm}^{2}$. In November, 1984, proposals were solicited from the other U.S. superconductor manufacturers and they were asked for their recommendations with respect to filament size and critical current density goals for the fine filament $R \& D$ program. These proposals and the scope of the fine filament R\&D program were discussed at a Superconductor Working Group meeting at LBL in January, 1985. Following this meeting, and after additional funding had been obtained, the fine filament program was expanded to include work at IGC and Oxford Superconducting Technology (OST) on double extrusion approaches, and at LBL on hydrostatic extrusion. Results on the first Supercon billet were obtained in July, 1985, and they showed a value of $\mathrm{J}_{\mathrm{C}}(5 \mathrm{~T})=2985 \mathrm{~A} / \mathrm{mm}^{2}$ for a filament size of $4 \mu \mathrm{m}$.(4) Based on these results, the target for the SSC fine filament $R \& D$ program was changed to a value of $J_{C}=2750 \mathrm{~A} / \mathrm{mm}^{2}$ at $5 T$ with a filament size of $2.5-5 \mu \mathrm{m}$. Progress toward this goal continued to look promising, so that the following values were selected for the SSC Conceptual Design Report $(5,6)$ (March, 1986): $\mathrm{J}_{\mathrm{C}}(5 \mathrm{~T}, 4.2 \mathrm{~K})=2750 \mathrm{~A} / \mathrm{mm}^{2}$; filament diam. $=5 \mu \mathrm{m}$. After much discussion and a careful study of the results for the LBL 1-m dipoles and the BNL $4.5 \mathrm{~m}$ dipoles, an operating field point of $6.6 \mathrm{~T}$ at $4.35 \mathrm{~K}$ was also selected. 
Using these values, a series of margins can be calculated. Three definitions of margins which are typically used are:

1) Critical current margin at a constant operating field

2) Critical current margin along the magnet load line

3) Temperature margin (operating vs. critical), at the operating field

The first two margins are calculated in SSC-MAG-160 by C. Taylor; $(7)$ the third margin can easily be calculated using the analytical expression from G. Morgan (BNL SSC-MD-84), and has been obtained for several cases by C. Quigg and M. Tigner ${ }^{(8)}$.

The important point to note is that these "margins" defined in this manner include a number of real effects which will act to limit magnet performance. These are also listed in SSCMAG-160. Two of these factors will be discussed here, since they are important in the development of a working SSC cable specification.

In the process of converting strands with a critical current density of $2750 \mathrm{~A} / \mathrm{mm}^{2}$ to cable, a certain amount of degradation occurs. In the past, this has been as high as $15-20 \%$;

however, as wire quality and cable manufacturing have improved, this has decreased. The difference in strand critical current vs. cable critical current also depends on the method of measurement and corrections applied to the measurements.(9) Using these test methods, in which cable self-field effects are included, but wire self-field effects are not included, and for the applied field perpendicular to the wide face of the cable, the recent degradation values are typically less than 5\%. In the present version of the SSC cable specification SSC-MAGM-4142, Rev. 2, a value of $5 \%$ was used for the maximum allowable degradation in cabling, for both the inner and outer cable.

In order to specify a minimum critical current, another factor must be taken into account; during the manufacturing process, the $\mathrm{Cu} / \mathrm{SC}$ ratio can vary from one end of the wire to the other. In order to maintain an acceptable yield, the $\mathrm{Cu} / \mathrm{SC}$ ratio is permitted to vary \pm 0.1 ; this is taken into account in converting the $\mathrm{J}_{\mathbf{C}}$ value into a minimum $\mathrm{I}_{\mathbf{C}}$ value for the cable.

The following is a step by step procedure used to convert from the Conceptual Design Report $\mathrm{J}_{\mathrm{C}}$ value to the present $\mathrm{SSC}$ cable minimum $\mathrm{I}_{\mathrm{C}}$ values:

1) Find the Jc value at the high field point in the dipole:

$$
\begin{aligned}
& \mathrm{J}_{\mathrm{C}}(7 \mathrm{~T}, 4.2 \mathrm{~K})=1650 \mathrm{~A} / \mathrm{mm}^{2} \text { Inner Cable } \\
& \mathrm{J}_{\mathrm{C}}(5.6 \mathrm{~T}, 4.2 \mathrm{~K})=2420 \mathrm{~A} / \mathrm{mm}^{2} \text { Outer Cable }
\end{aligned}
$$

These values are obtained by a linear interpolation between $2750 \mathrm{~A} / \mathrm{mm}^{2}$ at $5 \mathrm{~T}$ and $1100 \mathrm{~A} / \mathrm{mm}^{2}$ at $8 \mathrm{~T}$.

2) Find the minimum $I_{C}$ value based on these $J_{C}$ values and the maximum allowable

$\mathrm{Cu} / \mathrm{SC}$ ratio:

For inner cable, nominal $1.5 / 1$ ratio, minimum $\mathrm{I}_{\mathrm{C}}(7 \mathrm{~T}, 4.2 \mathrm{~K})=1650 \mathrm{~A} / \mathrm{mm}^{2} \cdot$ minimum area of superconductor $=7479 \mathrm{~A}$.

For outer cable, nominal $1.8 / 1$ ratio, minimum $\mathrm{I}_{\mathrm{C}}(5.6 \mathrm{~T}, 4.2 \mathrm{~K})=2420 \mathrm{~A} / \mathrm{mm}^{2} \cdot$ minimum area of superconductor $=8249 \mathrm{~A}$.

3) Find the minimum $I_{C}$ value with an allowance of $5 \%$ for cabling degradation: Inner cable minimum $\mathrm{I}_{\mathrm{C}}(7 \mathrm{~T}, 4.2 \mathrm{~K})=7479 \mathrm{~A} \cdot 0.95=7105 \mathrm{~A}$. Outer cable minimum $\mathrm{I}_{\mathrm{C}}(5.6 \mathrm{~T}, 4.2 \mathrm{~K})=7837 \mathrm{~A}$

An obvious question at this point is, "What are the prospects for increasing the dipole magnet margins?". With respect to critical current density, the recent production experience indicates that the wire manufacturers can meet the $2750 \mathrm{~A} / \mathrm{mm}^{2}$ value, but without a large margin; the values have been ranging from 2750 to $2950 \mathrm{~A} / \mathrm{mm}^{2}$. Indeed, the SSC spec. value is already the highest in the world, with HERA being approx. $2500 \mathrm{~A} / \mathrm{mm}^{2}$, RHIC is $2600 \mathrm{~A} / \mathrm{mm}^{2}$, and LHC is equivalent to $2450 \mathrm{~A} / \mathrm{mm}^{2}$. Also, we have observed an increase 
in strand stiffness with increased $\mathrm{J}_{\mathrm{c}}$, and this in turn makes cabling more difficult. We are continuing the push toward higher critical current densities in the SSC R\&D program, but it is premature to extrapolate those results to production quantities at this time. With respect to cable degradation, the values allowed for the SSC cable are again the lowest in the world; RHIC allows $10 \%$ and HERA allows $15 \%$. Further significant improvement in this area seems unlikely at this time, unless we decide to change the degree to which the cables are keystoned. The most significant parameter for increasing the operating margin appears to be the operating temperature, but that requires a discussion of trade-offs that are beyond the scope of this paper. The most obvious change in the conductors which could add to the present margin is a return to a copper to superconductor ratio of 1.3 in the inner layer cable.

\section{REFERENCES}

1. L. Chengren, W. Xiao-Zu, Z. Nong, IEEE Trans. on Magnetics, MAG-19, 284, 1983.

2. D. C. Larbalestier, A. W. West, W. Starch, W. Warnes, P. Lee, W. K. McDonald, P. O'Larey, K. Hemachalam, B. Zeitlin, R. Scanlan, and C. Taylor, IEEE Trans. on Magnetics, MAG 21, 1985.

3. LBL P.O. \#7456406, October, 1984.

4. E. Gregory, T. S. Kreilick, and J. Wong, "Fine Filamentary Materials for Accelerator Dipoles and Quadrupoles", in proceedings of the ICFA Workshop, P. Dahl, Ed. BNL Report 52006, pp. 85-88, 1986.

5. SSC Conceptual Design Report, SSC-SR-2020, March, 1986.

6. R. M. Scanlan, J. Royet, and R. Hannaford, "Evaluation of Various Fabrication Techiques for Fabrication of Fine Filament", NBT, Superconductors, IEEE Trans. on Magnetics, MAG-23, pp. 1719-1723, 1987.

7. C. E. Taylor, "Design "Margin" and the Effect of Different Copper-to-Superconductor

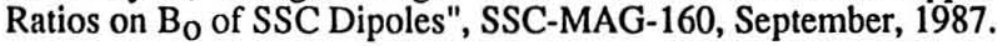

8. C. Quigg and M. Tigner, SSC Central Design Group Memo, May, 1988.

9. M. Garber and W. B. Sampson, SSC-N-488, March, 1988, and SSC.Cable Specification SSC-MAG-M-4142. 